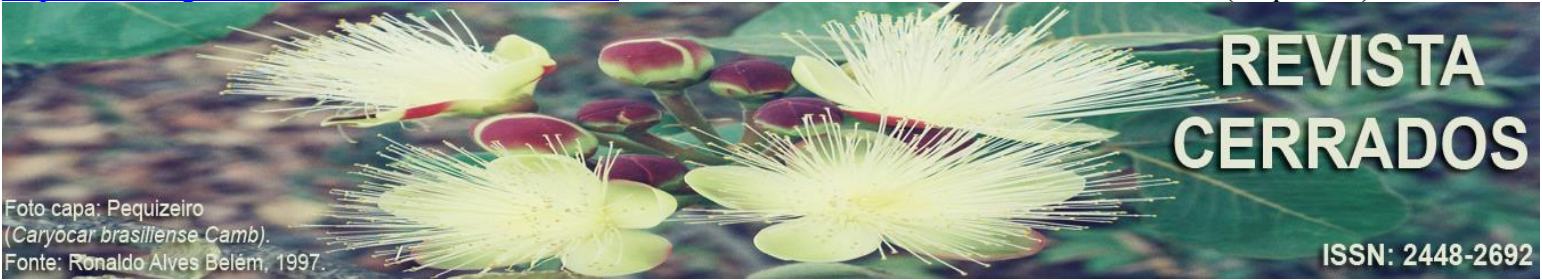

\title{
LEVANTAMENTO BATIMÉTRICO AUTOMATIZADO EM AMBIENTE LACUSTRE BRASILEIRO: o estudo de caso da Lagoa Maior
}

\section{AUTOMATED BATIMETRIC SURVEY IN BRAZILIAN LACUSTRE ENVIRONMENT: the Lagoa Maior case study}

\section{ENCUESTA BATIMÉTRICA AUTOMATIZADA EN EL ENTORNO LACUSTRE BRASILEÑO: el estudio de caso de Lagoa Maior}

\author{
Denivaldo Ferreira de Souza \\ Universidade Estadual de Campinas - UNICAMP, Campinas, \\ São Paulo, Brasil \\ E-mail: <deny1609@gmail.com>.

\begin{abstract}
André Luiz Pinto
Universidade Federal de Mato Grosso do Sul - UFMS, Três Lagoas,

Mato Grosso do Sul, Brasil

E-mail: <andrepintofontanetti@gmail.com>.
\end{abstract}

\begin{abstract}
RESUMO
Uma das atividades que ajudam a compreender a dinâmica hídrica em corpos d'água são os levantamentos batimétricos. Os procedimentos para realização, dependendo das condições físicas do ambiente ou econômica dos interessados, podem ser efetuadas de forma manual ou automatizada. Esse artigo retrata a experiência efetuada na lagoa maior urbana do município de Três Lagoas/MS, no ano de 2015. Os procedimentos metodológicos foram feitos em duas etapas, iniciou com uma operação em campo adotando o procedimento automatizado com auxílio de um ecobatímetro e gps, finalizando com a aferição e elaboração dos resultados em laboratório. A partir das aplicações dos procedimentos metodológicos propostos, obteve dois produtos cartográficos digitais, o mapa batimétrico e o modelo digital em três dimensões. $\mathrm{O}$ comprimento máximo encontrado foi de $809,2 \mathrm{~m}$, a profundidade máxima $1,80 \mathrm{~m}$, a profundidade média 0,65m, em uma área de 417.782,5 $\mathrm{m}^{2}$. Observou que há um assoreamento progressivo confirmado na Lagoa Maior, já que trabalhos realizados em 2002 constataram uma profundidade máxima de 3 metros. Isso poderá gerar problemas como a diminuição da vida aquática e a probabilidade de secagem do leito no período da estiagem.
\end{abstract}

Palavras-chave: Batimetria. Três Lagoas. Lagoa urbana. Modelagem 3d. Ecobatímetro. 


\begin{abstract}
One of the activities that help to understand the water dynamics in bodies of water are bathymetric surveys. The procedures for carrying out, depending on the physical conditions of the environment or economic of the interested parties can be carried out manually or automatically. This article portrays the experience carried out in the largest urban pond in the municipality of Três Lagoas/MS, in 2015. The methodological procedures were carried out in two stages, started with an operation in the field adopting the automated procedure with the aid of an echo sounder and gps, ending with the measurement and preparation of the results in the laboratory. From the applications of the proposed methodological procedures, he obtained two digital cartographic products, the bathymetric map and the digital model in three dimensions. The maximum length found was $809.2 \mathrm{~m}$, the maximum depth $1.80 \mathrm{~m}$, the average depth $0.65 \mathrm{~m}$, in an area of $417,782.5 \mathrm{~m}^{2}$. He noted that there is confirmed progressive silting in Lagoa Maior, since works carried out in 2002 found a maximum depth of 3 meters. This may cause problems such as the decrease in aquatic life and the probability of drying the bed during the dry season.
\end{abstract}

Keywords: Bathymetry. Três Lagoas. Urban pond. 3d modeling. Echo sounder.

\title{
RESUMEN
}

Una de las actividades que ayudan a comprender la dinámica del agua en los cuerpos de agua son los estudios batimétricos. Los procedimientos para llevar a cabo, dependiendo del entorno físico o las condiciones económicas de las partes interesadas, pueden llevarse a cabo de forma manual o automática. Este artículo retrata la experiencia llevada a cabo en la laguna urbana más grande del municipio de Três Lagoas/MS, en 2015. Los procedimientos metodológicos se llevaron a cabo en dos etapas, comenzando con una operación en el campo adoptando el procedimiento automatizado con la ayuda de un ecosonda y gps, terminando con la medición y preparación de los resultados en el laboratorio. A partir de las aplicaciones de los procedimientos metodológicos propuestos, obtuvo dos productos cartográficos digitales, el mapa batimétrico y el modelo digital en tres dimensiones. La longitud máxima encontrada fue $809.2 \mathrm{~m}$, la profundidad máxima $1.80 \mathrm{~m}$, la profundidad promedio $0.65 \mathrm{~m}$, en un área de $417,782.5 \mathrm{~m}^{2}$. Señaló que hay un sedimento progresivo confirmado en Lagoa Maior, ya que los trabajos realizados en 2002 encontraron una profundidad máxima de 3 metros. Esto puede causar problemas como la disminución de la vida acuática y la probabilidad de secar el lecho durante la estación seca.

Palabras-clave: Batimetría. Três Lagoas. Laguna urbana. Modelado 3D. Ecosonda.

\section{INTRODUÇÃO}

Trabalhos com abordagens em ambientes limnológicos vêm sendo desenvolvidos no Brasil há mais de um século. Esses estudos limnológicos, envolvendo corpos lóticos e lênticos, possuem grande significado nos âmbitos ecológico, econômico e social, pois o gerenciamento, conservação e recuperação dos sistemas aquáticos são de importância 
Levantamento batimétrico automatizado em ambiente lacustre brasileiro: o estudo de caso da Lagoa Maior

fundamental para a vida, com reflexos na economia, sociedade, usos múltiplos das águas, representando um bem-estar socioambiental (TUNDISI \& MATSUMURA-TUNDISI, 2008).

O processo de urbanização aos arredores de corpos lênticos surgiram pela necessidade de uma melhor sobrevivência para o ser humano, e o processo de evolução humana se fez nessas relações (ESTEVES, 1998). A necessidade de água para inicialmente o consumo e logo depois a agricultura propiciou a instalação de povoados as margens de rios e lagos/as. Desde então, o crescimento histórico da sociedade manipulou a forma de ocupação arquitetônica e o processo de aglomeração das cidades (STRASKRABA \& TUNDISI, 2000).

No início das vilas no Brasil o abastecimento da água para o consumo era feito por açudes próximos as vilas, com o avanço de técnicas de engenharia esse abastecimento de água passou a ser através da extração em aquíferos e rios mais distantes, ligando-os com galerias para servir a população (CORDEIRO, 2013). Em consequência, a utilização de lagos e lagoas para abastecer as cidades tornou-se desnecessária. Surge a partir de então, o conceito de um ambiente para harmonia paisagística natural dentro das cidades (TUNDISI \& MATSUMURA-TUNDISI, 2008).

Os impactos das atividades humanas nos corpos lénticos urbanos podem gerar uma série de problemas em seu ecossistema aquático. Nesta perspectiva, as pesquisas limnológicas têm despertado interesse crescente, visto que seus resultados podem ser amplamente aplicados para a conservação do ambiente aquático. E, em conformidade com Lima et al (2013) uma ferramenta de grande importância para o conhecimento das características morfométricas de lagos e açudes é a elaboração de cartas batimétricas, que possibilitam maior entendimento da estrutura e do funcionamento dos ambientes aquáticos.

\section{LEVANTAMENTO BATIMÉTRICO}

Uma das atividades que ajudam a compreender a dinâmica hídrica em corpos d'água são os levantamentos batimétricos. Esses levantamentos são cruciais para a navegação, além de serem necessários para as modelagens hidrodinâmicas e acompanhamento de processos de sedimentação ou assoreamento em qualquer corpo aquoso (Romano et. al., 2012). A batimetria é o conjunto dos princípios, métodos e convenções utilizados para determinar a medida do contorno, da dimensão e da posição relativa da superfície submersa, dos mares, rios, lagos, represas e canais (ALVARES et. al. 2001; PEREIRA \& BARACUHY, 

2008).

Os levantamentos batimétricos, dependendo das condições físicas do ambiente ou econômica dos interessados, podem ser efetuadas de forma manual, utilizando-se de varas e cordas ou de tecnológica automatizada, através de instrumentos a laser ou de ondas sonoras e/ou eletromagnéticas, resumidamente, tornaram os processos mais práticos e precisos, diminuindo o tempo para a obtenção dos resultados (IHO, 2005).

Uma das maiores dificuldades em levantamentos batimétricos sempre foi o controle do posicionamento planimétrico da embarcação de sondagem, em razão da impossibilidade de se materializar pontos estáveis de observação e tampouco efetuar medições repetidas, para um posterior ajustamento das profundidades (RAMOS, 2007; FERREIRA et. al., 2012).

A análise batimétrica possibilita a obtenção de um mapa de profundidade, garantindo uma maior segurança na correta tomada de decisões que visem o uso e a gestão sustentável de um determinado corpo hídrico, sendo fundamental na elaboração de estudos aquícolas, navegação, dragagem e na prática da atividade pesqueira ou de lazer. Além de subsidiar estes estudos, auxilia na determinação da capacidade de suporte, no qual se estima a possibilidade da inserção de projetos aquícola de modo sustentável, a partir da análise do nível de impacto sobre um ecossistema (FORTALEZA, 2007; JAWAK et. al., 2015).

A partir do crescimento dos aglomerados urbanos no mundo, gerando consecutivo aumento do consumo de água, o gestor, particular ou público, necessita com precisão e a tempo real, conhecimento do volume de água disponível e da sua qualidade. Cada vez mais novos reservatórios de águas são edificados para atender a demanda de consumo doméstico comercial, industrial e energético (ESTEVES, 1998).

Diante disso, a necessidade de um periódico monitoramento do volume de água armazenada na Lagoa Maior, que associadas a duas outras menores dão o nome ao município de Três Lagoas, no estado de Mato Grosso do Sul - MS, levaram a realização de um levantamento batimétrico automatizado no local. Podendo servir de base para batimetrias futuras em prol de melhorias e diminuição de custos.

\section{ÁREA DE ESTUDO}

O município de Três Lagoas, localizado na porção leste do estado de MS, possui uma Revista Cerrados, Montes Claros/MG, v. 18, n. 02, p. 536-552, jul./dez.-2020. 
SOUZA, D. F.; PINTO, A. L.

Levantamento batimétrico automatizado em ambiente lacustre brasileiro: o estudo de caso da Lagoa Maior

população estimada em 118 mil habitantes (IBGE, 2019). Denominada como a "Cidade das Águas" devida sua localização ser passagem e encontro de vários rios como o rio Paraná e rio Sucuriú. O município de Três Lagoas (MS) apresenta um dinamismo econômico em função da transição da agropecuária para a indústria e também por causa da expansão da silvicultura (eucalipto), levando a denominação de "capital mundial da celulose". Recentemente a industrialização contribuiu com o crescimento da população urbana, sendo o terceiro município com maior população no Mato Grosso do Sul (TRÊS LAGOAS, 2020).

O perímetro urbano é caracterizado pela presença de três lagoas que historicamente serviram de inspiração para o nome do município, fundado em 1915. Dentre as três lagoas urbanas, à Lagoa Maior possui uma maior participação na dinâmica da cidade. A mesma é compreendida sob as coordenadas $51^{\circ} 43^{\prime} 12.34^{\prime \prime}$ e $51^{\circ} 42^{\prime} 44.31^{\prime \prime}$ de longitude oeste, e $20^{\circ}$ $46^{\prime} 45.82^{\prime \prime}$ e $20^{\circ} 47^{\prime} 11.10^{\prime \prime}$ de latitude sul. Corresponde ao segundo ponto topograficamente menos elevado do perímetro urbano com uma altitude de $315 \mathrm{~m}$ acima do nível marítimo. A área da lâmina de água é de aproximadamente $418.000 \mathrm{~m}^{2}\left(488.000 \mathrm{~m}^{2} \mathrm{com}\right.$ a orla) e a rede de drenagem que abastece à Lagoa Maior possui $14 \mathrm{~km}^{2}$, Figura 1.

Figura 1: Mapa de localização da área de estudo, Lagoa Maior em Três Lagoas/MS, tomando referência a macro para a micro localidade utilizando imagem área gratuita de satélite

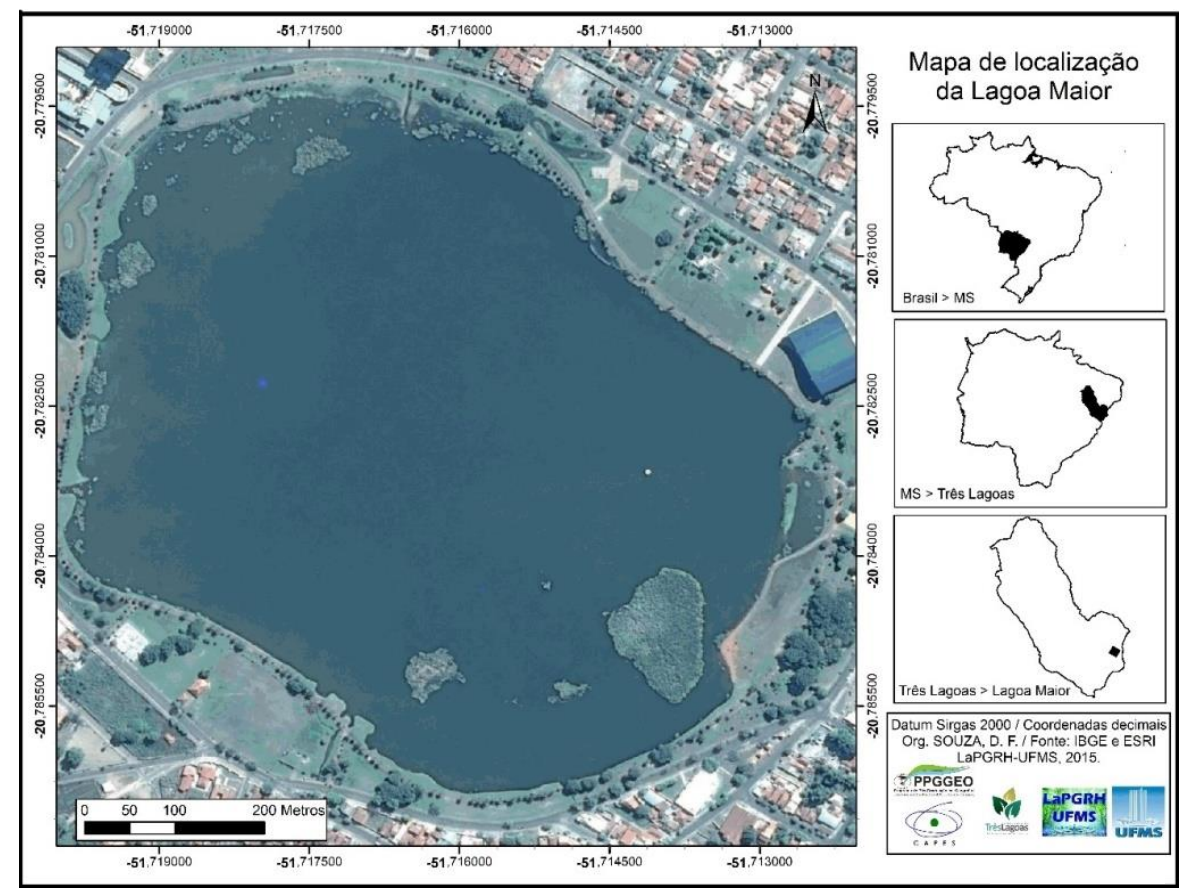

Fonte: Autores, 2015.

Revista Cerrados, Montes Claros/MG, v. 18, n. 02, p. 536-552, jul./dez.-2020. 
Levantamento batimétrico automatizado em ambiente lacustre brasileiro: o estudo de caso da Lagoa Maior

A Lagoa Maior está classificada como uma Área de Preservação Permanente (APP) urbana, o Ministério do Meio Ambiente brasileiro busca através dessas áreas possibilitar a valorização da paisagem e do patrimônio natural. Esses espaços exercem, do mesmo modo, funções sociais e educativas relacionadas com a oferta de campos esportivos, áreas de lazer e recreação, oportunidades de encontro, contato com os elementos da natureza e educação ambiental (voltada para a sua conservação), proporcionando uma maior qualidade de vida às populações urbanas, que representam 84,4\% da população do país (MMA, 2015).

A APP da Lagoa Maior está inserida na área central da cidade e corresponde ao segundo ponto topograficamente mais baixo no perímetro urbano com 319 mamsl. O entorno é ocupado por áreas de recreações como pista de caminhada, academias ao ar livre, playgrounds infantis, campos de futebol e rúgbi, pista de skate, quadras de vôlei, e entre outras instalações. Há também aos arredores vários comércios, em especial bares e restaurantes, algumas residências de alto padrão pelo fato da região ser centralizada tornandoa economicamente bem valorizada. Todas essas opções transformou o local no mais frequentado pela população residente e flutuante em Três Lagoas.

Os procedimentos da batimetria foram feitos em dois ambientes, iniciou-se com um método operacional em campo simplificado em três etapas, posteriormente, finalizou-se em gabinete, onde as etapas concluintes de aferição, elaboração e análise dos resultados fizeram-se.

\section{MATERIAIS E MÉTODOS}

\section{Método Operacional de Campo}

A operação em campo foi realizada no verão de 2015, mais especificamente no dia 21 de janeiro, no período da manhã, em etapas previamente elaboradas pelos autores. A primeira etapa consiste de posse de um barco com motor elétrico para evitar poluição oriundas da queima de determinados combustíveis e remo para auxiliar à mobilidade. A segunda etapa inicia com o direcionamento de 6 retas de pontos que foram mensurados (3 longitudinais e 3 transversais) de borda a borda da lâmina d'agua. Embarcado, a terceira etapa realizada inicia com as coletas de dados denominados $\mathrm{X}$ (longitude), Y (latitude) e Z (profundidade) mensurados de 10 em 10 metros, totalizando 397 pontos. A Figura 2 ilustra a 
SOUZA, D. F.; PINTO, A. L.

Levantamento batimétrico automatizado em ambiente lacustre brasileiro: o estudo de caso da Lagoa Maior

espacialização dos 6 transectos pontuais aplicados em todo o espelho d'agua.

Figura 2: Transecto com malha de pontos para obtenção do levantamento batimétrico da Lagoa Maior, Três Lagoas/MS

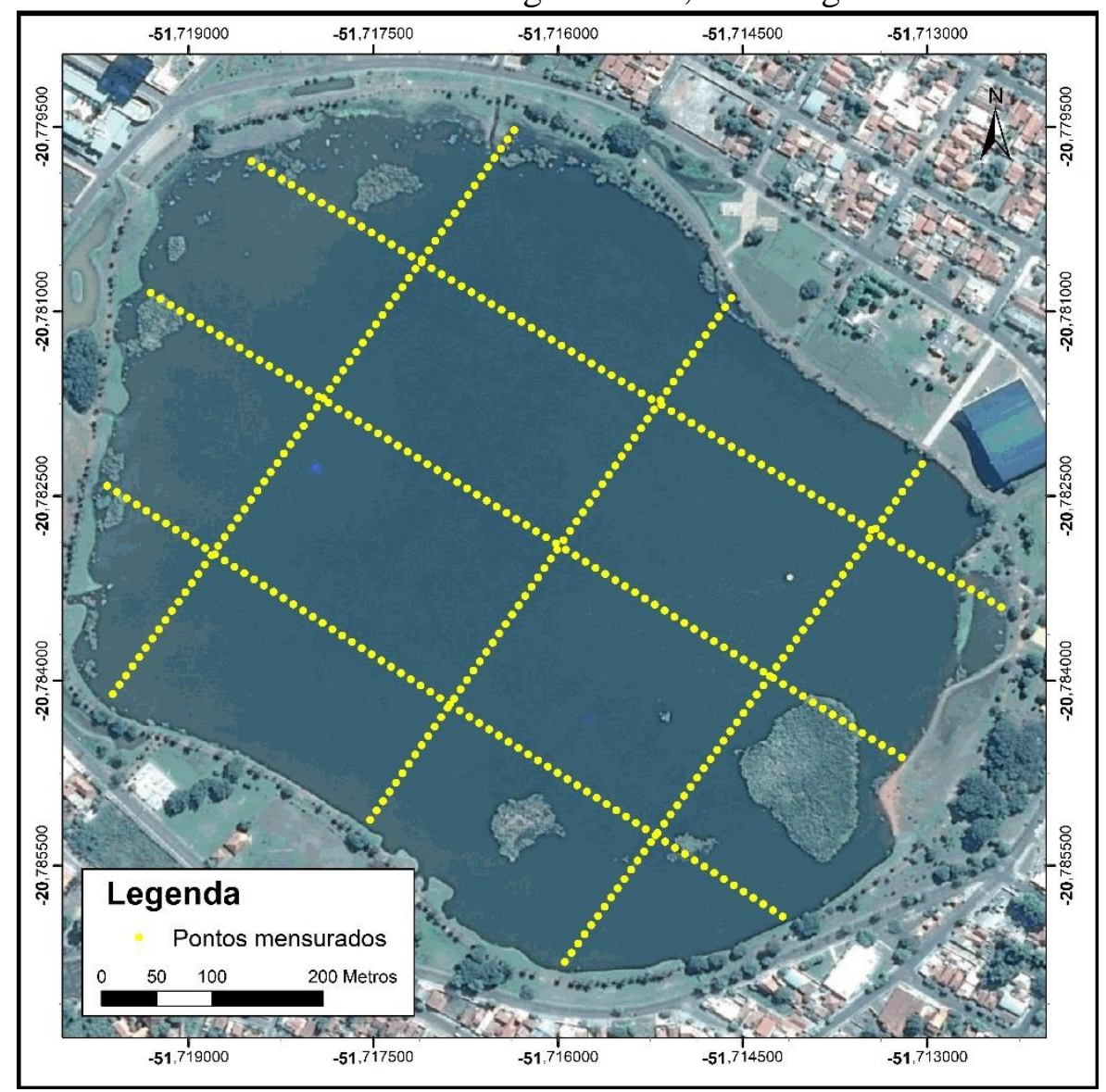

Fonte: Autores. 2015.

Na Lagoa Maior é visível a presença de um aglomerado de macrófitas aquáticas em forma de ilha flutuante (histossolo) na margem direita sob um dos transectos. Como a imagem de satélite fornecida pelo Google Earth Pro é datada em 26/07/2013, no dia da coleta esse histossolo estava deslocado para o sul não interferindo na mensuração.

Os equipamentos utilizados foram um sonar CUDA 300, um GPS Garmin modelo 76CSX, um barco de alumínio Marinne, um motor elétrico MINN KOTA Turbo alimentado por uma bateria automotiva Júpiter de 48 amperes. O Sonar CUDA 300 é também um ecobatímetro, pois determina a profundidade através da emissão de um laser pelo sensor acoplado a popa do barco ou em algum suporte, e utilizando o cálculo de tempo/velocidade determina a profundidade local. $\mathrm{O}$ visor é monocromático e bem didático facilitando a coleta de dados, e seu funcionamento acontece por meio de uma bateria de 12 volts a bordo. 
Levantamento batimétrico automatizado em ambiente lacustre brasileiro: o estudo de caso da Lagoa Maior

De acordo com Pio (2008) a batimetria por ecobatímetro são lentos e de alto custo, uma vez que necessitam de embarcação e pessoal capacitado, apesar disso possui algumas vantagens como: Os dados são registrados de forma contínua, tipo varredura, em papel ou meio magnético; Pode ser utilizado praticamente todas as situações de velocidade, permitindo o levantamento de corredeiras; O levantamento é feito com embarcação em movimento, sendo o posicionamento das verticais de controle feito com marcados especial; Por fim, o ecograma permite inferir sobre a formação e característica do leito.

O desenvolvimento e implantação dos sistemas GPS, sistema de posicionamento global que através de sinais recebidos e emitidos por satélites informa a posição local, tornaram possível a navegação baseada em coordenadas a usuários comuns de ambiente aquático e ambiente terrestre, pois qualquer ponto da superfície terrestre pode ser definido através de suas coordenadas.

Há sobretudo duas categorias de coordenadas, a primeira seria as coordenadas geográficas, onde os valores logrados são dois ângulos definidos como latitude e longitude. Uma segunda categoria é denominada UTM (Universal Transversa de Mercator), nesse sistema de coordenadas os valores logrados são medidas de distâncias, possibilitando uma utilização mais simples, além disso esse sistema assegura a identificação com uma precisão de 1 metro de qualquer ponto da superfície terrestre (FRIEDMANN, 2009; BENEDETTI, 2011).

A obtenção dos valores necessários para à batimetria, como a profundidade e coordenadas de pontos na superfície da lâmina d'agua, deu-se com o uso de um GPS Garmin 76CSX. Esse aparelho apresenta erro de 1,5m e através dele foi executada, com intervalos de 10 em 10m, a coleta e mensuração dos dados de localização no interior da lagoa.

Figura 3: Sensor submerso para captação de dados (A); resultado fornecido no visor do sonar (B); metragem, longitude e latitude sendo captada pelo gps (C)
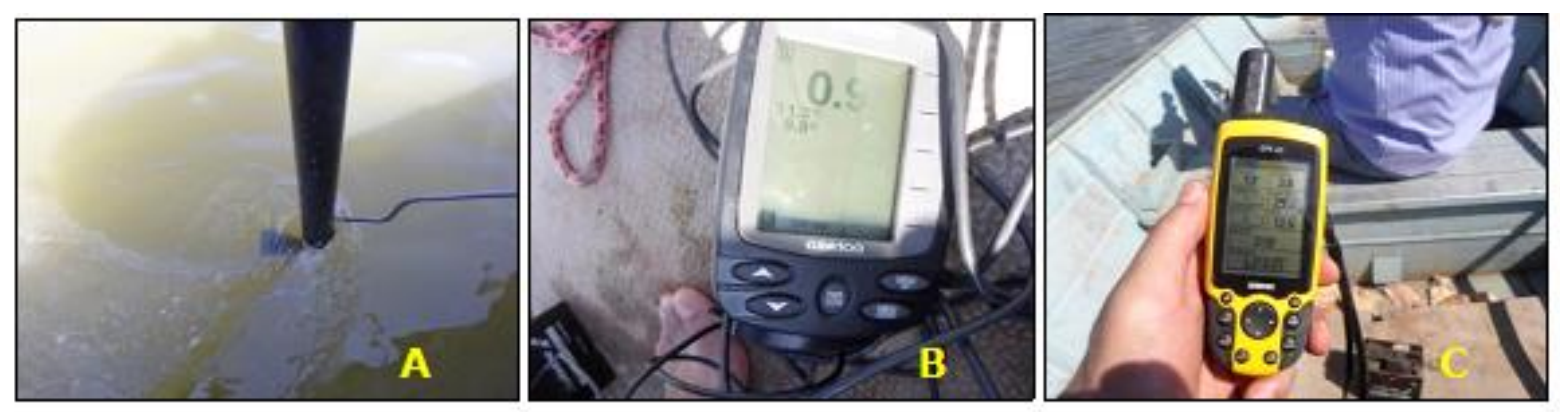

Fonte: Autores, 2015. 
SOUZA, D. F.; PINTO, A. L.

Levantamento batimétrico automatizado em ambiente lacustre brasileiro: o estudo de caso da Lagoa Maior

O motor de popa elétrico Minn Kota Turbo possui 5 velocidades e uma potência de $36 \mathrm{lbs}$, indicado para barcos de até 16 pés (5,5 metros), o barco utilizado possuía 5 metros modelo alumínio Marinne. Com os equipamentos calibrados deu início aos transectos. As 6 retas foram percorridas com o sensor a laser do sonar ficando todo o tempo dentro d'água (necessário para a leitura dos dados pelo sensor), e sendo anotados de 10 em 10 metros os dados de longitude e latitude pelo GPS abordo, Figura 3. Todos os dados eram arquivados em um laptop in loco.

\section{Método Operacional de Laboratório}

Em gabinete, utilizando-se dos softwares Excel 2010 da Microsoft Corporation e Surfer 11, fornecido pela Golden Software, criou-se um mapa batimétrico projetado em duas dimensões destacando à profundidade auxiliado com a criação de dois perfis transversais e um perfil longitudinal e um modelo digital batimétrico em três dimensões (3D) georreferenciado caracterizando à Lagoa Maior.

A obtenção do mapa batimétrico começou com a geração em Excel no formato de tabela de todos os 397 pontos cotados, cada ponto possuía coordenadas (X e Y) e profundidade $(Z)$. Assim, descriminados todos os pontos, permitiu a exportação da tabela para dentro do Surfer 11. Dentro do software todos os dados são convertidos para o formato padrão do programa, surfer grid, e através da ferramenta New Contour Map onde o programa aplica o algoritmo de interpolação do inverso do quadrado da distância permitindo a criação das curvas isobatimétricas com intervalos de 10 metros.

A realização do modelo digital em três dimensões obteve-se tendo como base o mapa batimétrico já produzido. Os três valores já inseridos, X, Y e Z, aplicou-se o recurso da ferramenta New 3D Surface para gerar o modelo, e padronizando com as cores que o programa fornece para classes batimetrias de profundidade, a Figura 4 ilustra esses processos. 
Figura 4: Processos realizados em gabinete.

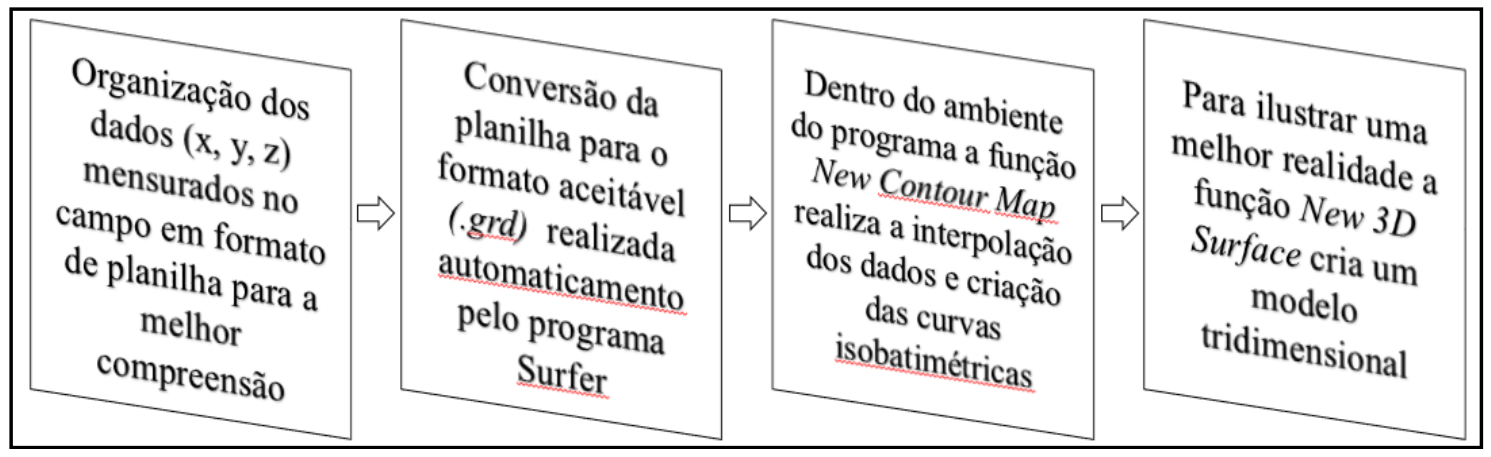

Fonte: Autores, 2020.

\section{RESULTADOS}

O primeiro resultado que se fez necessário para caracterizar à Lagoa Maior foi a medição de vários indicadores métricos possíveis em gabinete, Tabela 1.

Tabela 1: Atributos aferidos na Lagoa Maior.

\begin{tabular}{cccccc}
\hline & $\boldsymbol{C m}(\boldsymbol{m})$ & $\boldsymbol{L m}(\boldsymbol{m})$ & $\boldsymbol{A}\left(\boldsymbol{m}^{2}\right)$ & $\boldsymbol{P m}(\boldsymbol{m})$ & $\boldsymbol{P}(\boldsymbol{m})$ \\
\hline Lagoa Maior & 809,2 & 601,7 & $417.782,5$ & 1,8 & $2.505,2$ \\
\hline
\end{tabular}

Onde, Cm é Comprimento máximo; Lm é Largura máxima; A é Área; Pm é Profundidade máxima; P é Perímetro; Todos em unidade de medida de metros (m).

A partir das aplicações dos procedimentos metodológicos propostos, obteve dois produtos cartográficos digitais: o mapa batimétrico e o modelo digital em três dimensões. $\mathrm{O}$ mapa batimétrico mostra as classes de profundidade, com intervalos de $20 \mathrm{em} 20 \mathrm{~cm}$, apresentando profundidade média de 65 centímetros, e o ponto mais profundo atingiu 1,80 metros, localizado no entorno da fonte luminosa, Figura 6. As menores profundidades, entre 0 a $40 \mathrm{~cm}$, foram mensuradas no lado norte, noroeste e oeste da Lagoa Maior, próximas ao restaurante e choperia Muller, hotel OT e pista de Skate, e a leste, próximas ao Ginásio Poliesportivo e campos de vôlei, todos locais são de grande presença da população.

O lado leste da Lagoa Maior apresentou a maior alternância na profundidade, consequentemente, um leito com relevo mais heterogênico, certamente devido ao escavamento para a instalação da fonte luminosa. A apresentação do modelo digital em três dimensões foi elaborada para melhor ilustrar e facilitar a compreensão da distribuição da 
Levantamento batimétrico automatizado em ambiente lacustre brasileiro: o estudo de caso da Lagoa Maior profundidade que se encontra à Lagoa Maior em janeiro de 2015, bem como no cálculo da área e do volume de água em cada classe de profundidade, Figura 5.

A variação da profundidade partindo do lado noroeste para sudeste, segundo o perfil longitudinal 1, aponta que somente após percorrer 250 metros adentro da lâmina d'agua é que se consegue a profundidade de 1 metro, Figura 6, isso evidencia que este lado está sofrendo um possível assoreamento natural e/ou por influência antrópica. Já os perfis transversais 2 e 3, reforçam esta afirmação, pois o perfil transversal 2 tem sua maior profundidade de $90 \mathrm{~cm}$, enquanto que o perfil transversal 3, chega até 1,50 $\mathrm{m}$.

Figura 5: Modelo batimétrico em três dimensões resultante da batimetria realizada na Lagoa Maior, município de Três Lagoas/MS, realçando a profundidade máxima em 1,8 metros em janeiro de 2015

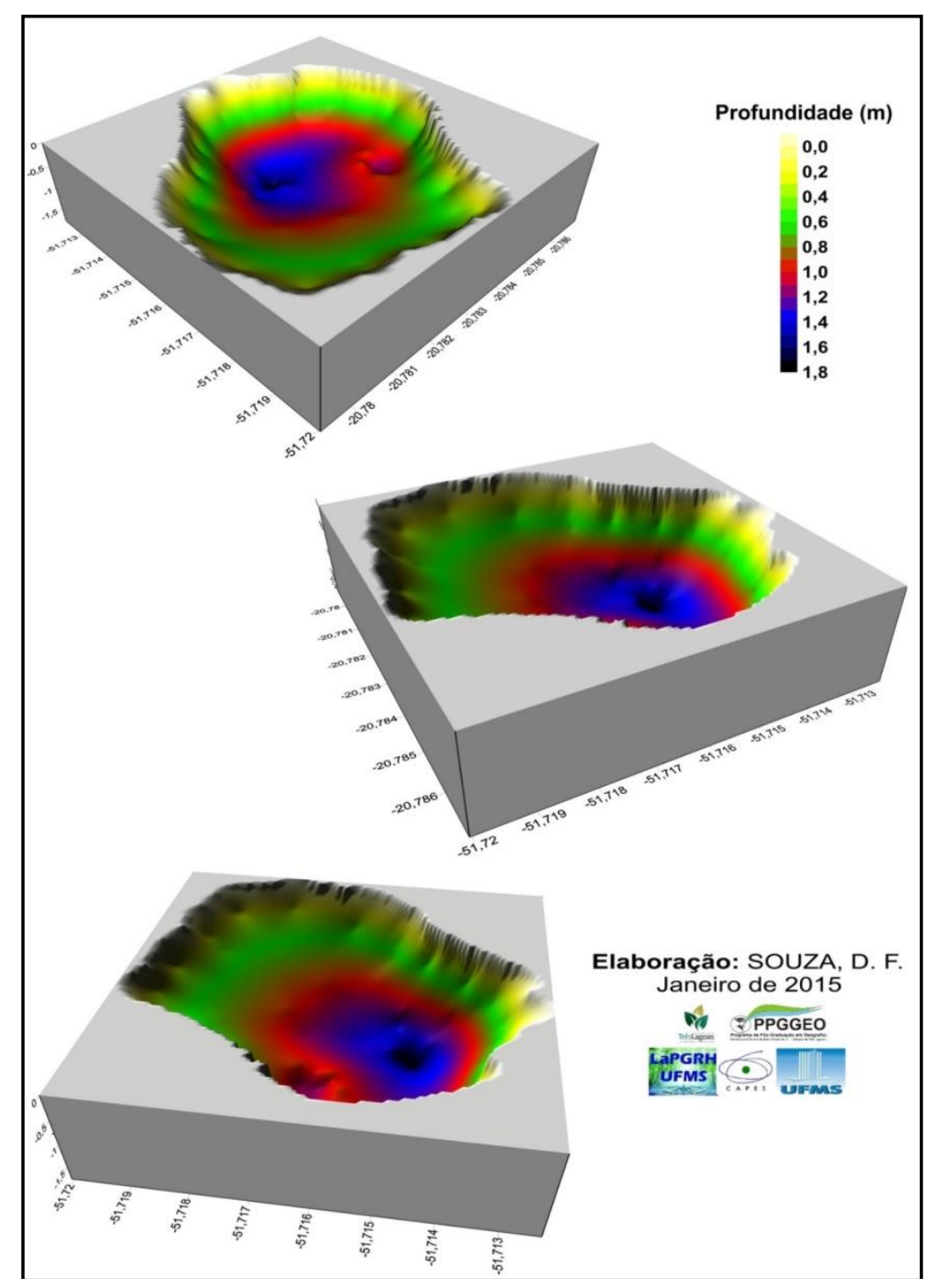

Fonte: Autores, 2015.

Revista Cerrados, Montes Claros/MG, v. 18, n. 02, p. 536-552, jul./dez.-2020. 
SOUZA, D. F.; PINTO, A. L.

Levantamento batimétrico automatizado em ambiente lacustre brasileiro: o estudo de caso da Lagoa Maior

Figura 6: Mapa batimétrico e perfis longitudinal e transversais resultantes da batimetria realizada na Lagoa Maior, município de Três Lagoas/MS, realçando o entorno da fonte luminosa como a mais profunda em janeiro de 2015.

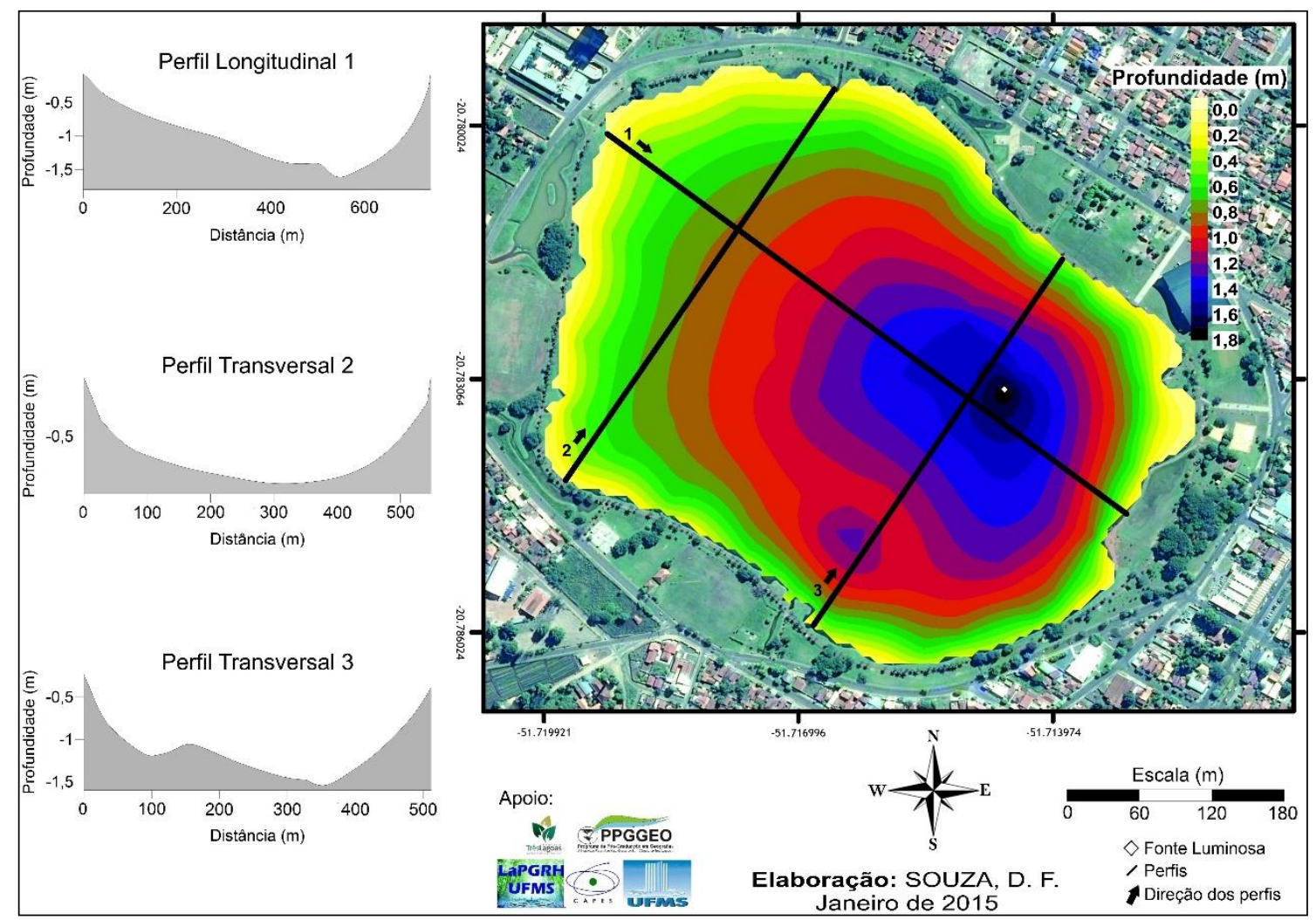

Fonte: Autores, 2015.

\section{Discussão}

Os reservatórios interceptam grande parte dos sedimentos transportados pelos rios em área rurais, e em áreas urbanas são responsáveis por armazenar o transporte oriundo da pluviometria. Estudos sedimentométricos normalmente são efetuados antes da construção da barragem para permitir uma previsão do volume a ser assoreado e da vida útil do reservatório. Para Santos (2001) o tempo de vida útil é contado desde a construção até que o reservatório fique assoreado, em uma condição que não serve aos propósitos para o qual foi construído.

O assoreamento progressivo confirmado na Lagoa Maior, já que trabalhos realizados em 2002 por pesquisadores da Universidade Federal de Mato Grosso do Sul demonstrou uma profundidade máxima de 3 metros e em 2015 não passou de 1,80 metros, pode causar graves problemas como a diminuição da vida aquática e a probabilidade de seca do leito. 
SOUZA, D. F.; PINTO, A. L.

Levantamento batimétrico automatizado em ambiente lacustre brasileiro: o estudo de caso da Lagoa Maior

Identificou-se no local o escoamento dos sedimentos pela ação das águas pluviais sem controle como o principal agravante para o assoreamento, mas outras atividades auxiliam o avanço. A presença de pouca mata ciliar no entorno contribui com o efeito splash agindo no solo, e outro fator que foi observado é a degradação por pisoteio de animais, Figura 7, em sua ampla maioria por capivaras.

Figura 7: Solo danificado por pisoteio de animais em especial capivaras

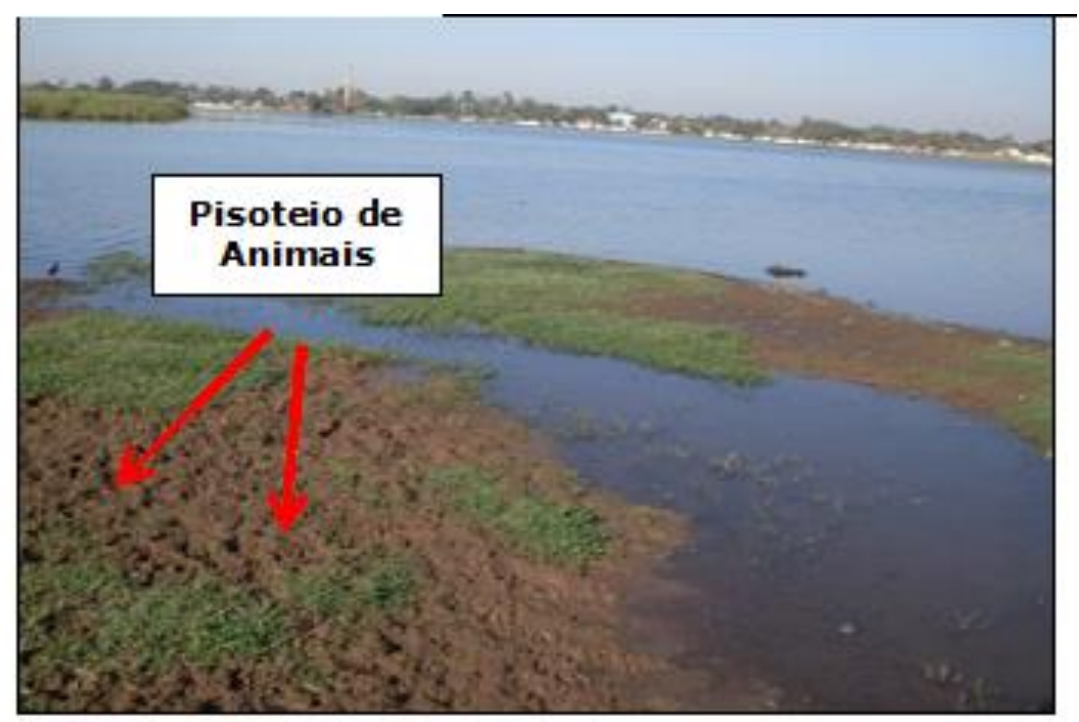

Fonte: Autores, 2016.

A ocupação sem planejamento vem acelerando este antigo processo através do desmatamento na orla e nas cabeceiras dos afluentes da Lagoa Maior e outras ações que acabam por expor as áreas à erosão; na construção de casas sem contenção de encosta. A região também sofreu com técnicas agrícolas inadequadas em períodos passados, quando se promoveram desmatamentos extensivos para dar lugar a áreas plantadas, impedindo grandes áreas de terrenos de cumprirem com seu papel natural de absorvedor de águas e aumentando a potencialidade do transporte de sedimentos.

O processo de assoreamento é um fenômeno muito antigo no planeta, surgimento equiparado ao período de formação dos mares e rios. Segundo Esteves (1998) sistemas hidrológicos lênticos ou lacustres não são elementos permanentes da paisagem da terra, pois eles são fenômenos de curta durabilidade na escala geológica, assim surgem e desaparecem no decorrer do tempo. Esse "tempo" corresponde a períodos de centenas de milhares ou milhões de anos, muito além da presença humana na terra. Portanto, a preservação visando 
SOUZA, D. F.; PINTO, A. L.

Levantamento batimétrico automatizado em ambiente lacustre brasileiro: o estudo de caso da Lagoa Maior uma harmonia sociedade e meio ambiente é fundamental.

Na localidade foi observado o despejo sistemático de esgotos domésticos e comercial, lançados, direta e indiretamente, nas margens da lâmina d'agua, é a provável causa das mortes da vida aquática constatada, Figura 8. Realçando que esse processo não deve ser confundido com o processo de assoreamento.

Figura 8: Mortandade de peixes presenciada na Lagoa Maior

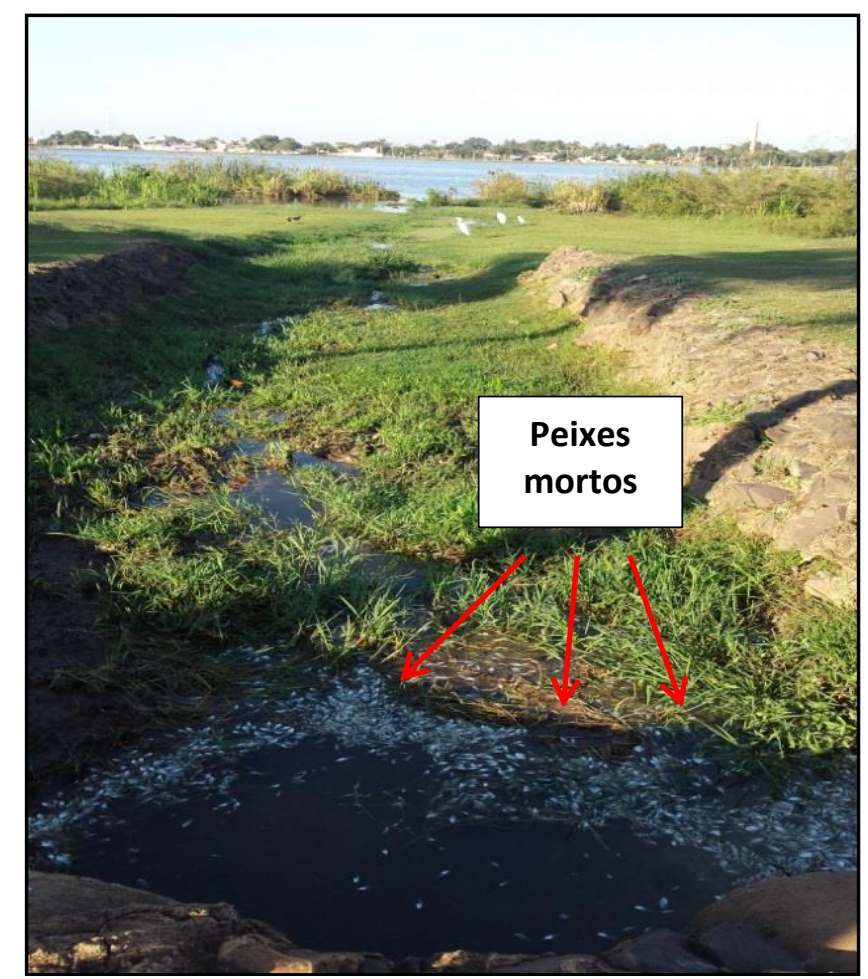

Fonte: Autores, 2016.

\section{CONSIDERAÇÕES FINAIS}

A utilização de recursos tecnológicos na pesquisa de campo tem auxiliado no avanço dos resultados, melhorado a praticidade de coletas, otimizando uma economia de tempo in loco, e na geração de dados confiáveis que possam ser elaborados regularmente, auxiliando nos monitoramentos hídricos. Além do mais, a metodologia aplicada pode contribuir para trabalhos futuros envolvendo levantamentos batimétricos em sistemas lacustres.

À Lagoa Maior é hoje definida como Área de Preservação Permanente e projetos buscam a mudança do local para uma Unidade de Conservação de Uso Integral, Revista Cerrados, Montes Claros/MG, v. 18, n. 02, p. 536-552, jul./dez.-2020. 
Levantamento batimétrico automatizado em ambiente lacustre brasileiro: o estudo de caso da Lagoa Maior

transformando à Lagoa Maior em Monumento Natural. A mudança traria melhorias ambientais mediante o novo código florestal brasileiro, mas a sociedade local deve pensar e relacionar a realidade ponderando à Lagoa Maior que temos, à Lagoa Maior que queremos e à Lagoa Maior que podemos ter.

\section{AGRADECIMENTOS}

Os Autores agradecem a Coordenação de Aperfeiçoamento de Pessoal de Nível Superior Capes pelo apoio fornecido.

\section{REFERÊNCIAS}

ÁlVARES, M. T.; FERNANDES, S. M.; PIMENTA, M. T.; VERÍSSIMO, M. R. Monitorização Batimétrica em Albufeiras. ESIG2001, Instituto da Água - Direção de Serviços de Recursos Hídricos, Lisboa, Portugal, 2001. 8p.

BENEDETTI, P. E. Caracterização geoambiental dos sedimentos da lagoa de Jacarepaguá, RJ. 2011. 235 f. Dissertação (Mestrado em Engenharia Civil), PUC-RIO, Rio de Janeiro, RJ, 2011.

BRASIL. Ministério do Meio Ambiente - MMA. Sistema Nacional de Unidades de Conservação (SNUC). Disponível em: <http://www.mma.gov.br/legislacao >. Acesso em fevereiro de 2020.

CORDEIRO, S. F. O. Avaliação do grau de trofia das águas do reservatório da usina hidrelétrica Barra dos C - GO. 2013. 95 f. Dissertação (Mestrado em Geografia), Programa de Pós-Graduação em Geografia/PPG-GEO - Universidade Federal de Goiás, Jataí/GO, 2013.

ESTEVES, F. A. Fundamentos de Limnologia. Interciência, 2ed, Rio de Janeiro, 1998. $602 p$.

FERREIRA, I. O.; RODRIGUES, D. D.; SANTOS, A. P. dos. Levantamento Batimétrico Automatizado Aplicado à Gestão de Recursos Hídricos. Estudo de caso: Represamento do Ribeirão São Bartolomeu, Viçosa - MG. IV Simpósio Brasileiro de Ciências Geodésicas e Tecnologias da Geoinformação. Recife/PE, p. 001-008, 06-09 de maio de 2012.

FORTALEZA, Prefeitura Municipal. Relatório do Mapeamento Batimétrico. Programa Lagoas de Fortaleza. Fortaleza/CE, 2007. 22 p.

FRIEDMANN, R. M. P. Orientação como esporte e corridas de orientação. In:

FRIEDMANN, R. M. P. Fundamentos de orientação, cartografia e navegação terrestre. 3ed. Curitiba: UTFPR, p. 59-82, 2009.

GOLDEN SOFTWARE, INC. Surfer. Version 11.0.642 (32bit). Colorado - USA, 2002. 
IHO, International Hydrographic Organization. Manual on Hydrography. Mônaco: International Hydrographic Bureau, 2005. 540p.

JAWAK, S. D.; VADLAMANI S. S.; LUIS, A. J. A Synoptic Review on Deriving Bathymetry Information using Remote Sensing Technologies: Models, Methods and Comparisons. Advances in Remote Sensing, [S./l.], v. 4, p. 147-162, 2015.

LIMA, J. R. C.; SHINOZAKI-MENDES, R. A.; ALMEIDA, A. Q. Estimativa da batimetria do açude do saco-pe com auxílio de dados orbitais. Eng. Agríc., Jaboticabal, v.34, n.5, p.1017-1023, set./out. 2013.

PEREIRA, J. P. G., \& BARACUHY, J.G. de V. Ecobatimetria: Teoria e Prática. Campina Grande: Gráfica Agenda, 2008. 84p.

PIO, S. B. Avaliação batimétrica da lagoa de decantação: Estação de tratamento de esgotos do município de Itapira. 2008. 55 f. Trabalho de Conclusão Curso (Graduação). Universidade São Francisco - UNIFRAN, 2008.

RAMOS, A. M. Aplicação, Investigação e Análise da Metodologia de Reduções Batimétricas Através do Método GPS Diferencial Preciso. 2007. 221 f. Dissertação (Mestrado em Ciências Geodésicas), Universidade Federal do Paraná - UFPR. Curitiba/PR, 2007.

ROMANO, A. \& DURANTI, P. Autonomous Unmanned Surface Vessels for Hydrographic Measurement and Environmental Monitoring. In Proceedings of the FIG Working Week 2012, Knowing to Manage the Territory, Protect the Environment, Evaluate the Cultural Heritage, Rome, Italy, p. 01-15, 06-10 May 2012.

SANTOS, I.; FILL, H. D.; SUGAI, M. R. B.; BUBA, H.; KISHI, R. T.; MARONE, E.; LAUTERT, L. F. Hidrometria Aplicada. Curitiba/PR: Instituto de Tecnologia para o Desenvolvimento, 2001. 188p.

STRASKRABA, M; \& TUNDISI, J. G. Gerenciamento da qualidade da água de represas. Editora ILEC - IIE, São Carlos/SP, 2000. 280p.

TRÊS LAGOAS. PREFEITURA MUNICIPAL. A cidade. 2020. Disponível em: <http://www.treslagoas.ms.gov.br/cidade/>. Acesso em: 11 jul. 2020.

TUNDISI, J. G. \& MATSUMURA-TUNDISI, T. Ecossistemas de águas interiores. In: REBOUÇAS, A. da C; BRAGA, B; TUNDISI, J. G. (org.). Águas doces no Brasil: capital ecológico, uso e conservação. Escrituras: São Paulo, 2006. p. 161-202. 
Denivaldo Ferreira de Souza - É Graduado em Geografia pela Universidade Federal de Mato Grosso do Sul (UFMS), Mestre em Geografia pela Universidade Federal de Mato Grosso do Sul (UFMS). Atualmente é Doutorando do Pós-graduação em Geografia da Universidade Estadual de Campinas (UNICAMP).

André Luiz Pinto - É Graduado em Geografia pela Universidade Estadual Paulista Júlio de Mesquita Filho (UNESP), Mestre e Doutor em Geociências e Meio Ambiente pela Universidade Estadual Paulista Júlio de Mesquita Filho (UNESP). Atualmente é Professor Titular da Universidade Federal de Mato Grosso do Sul (UFMS).

Artigo recebido em: 23 de julho de 2020.

Artigo aceito em: 14 de dezembro de 2020.

Artigo publicado em: 22 de dezembro de 2020. 